\title{
Sentiment and Stock Returns: A Case for Conventional and Islamic equities in Pakistan
}

\author{
Sana Tauseef ${ }^{1}$
}

\begin{abstract}
The study constructs market sentiment index over the period from August 2009 to June 2019 and examines the causality between market sentiment and returns for conventional and Islamic stocks in Pakistan. Using the firm-level data for all stocks listed on Pakistan Stock Exchange, market sentiment index is constructed as the first principal component of six variables: advances-to-decline, premium on dividends, price-to-earnings, relative strength, money flow and turnover rate. We employ the Vector auto-regression model to examine the two-way causal relationship between investor sentiment and aggregate stock return. Our results show that market sentiment has strong predictive power for subsequent conventional stock returns. Sentiment based trading actions of the investors cause persistence in conventional stock returns for one month; however, as these stocks become overpriced, the price movement reverses in two months' time. In contrast, we do not find any significant association between market sentiment and Islamic stock returns. Our findings are suggestive of different dynamics and investor behavior in Islamic financial markets of Pakistan and along with the existing literature documenting Islamic stocks performance to be at least as good as the conventional stock can be a comfort to the Muslim Investors and may serve as the catalyst to stimulate the growth of Islamic equities.
\end{abstract}

Keywords: Market sentiment, stock returns, Islamic, Pakistan

\section{Introduction}

Asset pricing literature has a long history and there is mounting empirical evidence that multiple risk factors, either individually or jointly, help explain a significant portion of variations in stock returns. Traditional finance argues that the risk factors are correctly priced in long run claiming market efficiency where the opportunities for rent seeking activities do not exist. On the contrary, behavioral finance proposes that mispricing may persist due to the existing limits to arbitrage and irrationality in investors' behavior (Barberis, Shliefer, \& Vishny, 1998; Barberis, \& Thaler, 2003).

1 Assistant Professor, Department of Finance, Institute of Business Administration (IBA), Karachi. Email: sasghar@iba.edu.pk

\section{ARTICLE HISTORY}

29 Jan, 2020 Submission Received 15 Jun, 2020 First Review

11 Sep, 2020 Second Review 25 Sep, 2020 Accepted 
Based on the behavioral finance proposition, investors are not fully informed and rational and their decisions are impacted by the biases they possess. Instead of being driven by information and calculations, such noise traders' actions are driven by their sentiments. With the advancement in the field of behavioral finance in recent years, studies have tried to capture the market sentiment, which could then be used as a factor to predict market return. Majority of the sentiment-based studies have reported that sentiment has substantial association with equity returns (Baker \& Wurgler, 2006; Baker \& Wurgler, 2007; Chen, Chong, \& Duan, 2010; Arif \& Lee, 2011; Gao, Ren, \& Zhang, 2018).

Pakistan Stock Exchange is an emerging equity market which has shown remarkable performance in many years over the last two decades. The status of the market was upgraded by Morgan Stanley in 2016 from frontier to emerging which enabled it to attract local and foreign investors. However, as a growing emerging market, it still lacks the desirable depth and sophistication in the trading behavior of investors. Given the features of Pakistan's equity market, the role of sentiment seems to be substantial. Sadaqat and Butt (2016) and Khan and Ahmad (2018) have studied the impact of sentiment on stock returns for Pakistan's market using different sets of proxy variables over different sample periods. Using the data over the period from 2001 to 2015, Sadaqat and Butt (2016) reported sentiment to have a positive contemporaneous effect and negative lagged effect on stock returns. On the contrary, Khan and Ahmad (2018) used the data over the period from 2006 to 2016 and reported that the impact of sentiment on stock returns is not instantaneous but is realized with a lag of three months.

The two studies from Pakistan's market confirm the dominating effect of sentiment on stock returns in Pakistan; however, their inconsistent findings warrants further research. Furthermore, the study periods used by earlier researches included the period of financial crisis that was characterized by very thin trading in Pakistan's equity market. Moreover, an autocratic political regime prevailed in Pakistan since mid-2001 till mid-2008 after which the democratic government took over. The study periods of previous studies combined pre-and post-crisis years and the years of autocratic and democratic political regimes. However, Haider, Din and Ghani (2011) documented that autocratic regimes in Pakistan experienced high economic growth, low inflation and better governance as compared to democratic regimes. Furthermore, Tauseef and Nishat (2018) reported contrasting returns for momentum based trading strategies in Pakistan over the two periods. Momentum returns were found to be positive in the pre-crisis period that was characterized by autocratic political regime and negative for the post-crisis period which was characterized by democratic political regime. Based on the evidence provided by Haider et al. (2011) and Tauseef 
and Nishat (2018), the market behavior may be time-specific. Considering this, we construct an investor sentiment index for Pakistan's market and measure the bi-directional relationship between investor sentiment and stock returns in Pakistan over the period from August 2009 to June 2019 which is the post-crisis period when the democratic regime prevailed.

We examine the influence of investor sentiment on conventional and Islamic stock returns. We perform a separate analysis for Islamic stocks in Pakistan motivated by the following facts. Islamic finance has grown substantially over the past decade across the world as well as in Pakistan. As per the Global Islamic Finance Report, global Islamic financial service industry grew at an average annual rate of 12.46 percent over the period 2009-18 and Pakistan held tenth position globally based on Islamic Finance Country Index 2019 (Edbiz Consulting, 2019). In June 2019, Islamic banking assets and deposits had a market share of 14.4 percent and 15.9 percent, respectively in the overall banking industry of Pakistan (State Bank of Pakistan, 2019) and there were 246 Shari'ah compliant stocks out of the total 546 stocks listed on Pakistan Stock Exchange (Pakistan Stock Exchange, 2019). Based on the gap between the potential and actual size of Islamic finance, it has a huge potential for growth in future years both locally as well as globally which makes it important to study the Islamic equity as a separate financial asset class.

Islamic finance industry operates on principles of Islamic Shari'ah. Since these principles are different from the ones on which conventional finance industry is based, findings regarding the asset pricing of conventional stocks cannot be generalized to Islamic stocks. Though the available literature on asset pricing globally is substantial, very few studies have been conducted to analyze the determinants of Islamic stock return (Masih, Kamil, \& Bacha, 2018). Specifically, sentiment is captured by separate macroeconomic variables in existing literature on Islamic financial markets. Furthermore, there is no study investigating the bi-directional causality of sentiment and Islamic stock returns. We fill these gaps in literature by examining the two-way association of sentiment with Islamic stock returns in Pakistan. Our study, thus, is a major contribution to the literature on Islamic financial markets. The study findings will help understand the role of sentiment in determining the returns on Pakistan's stocks in the post crisis period and will help to identify if the behavior of Islamic investors is influenced by the market sentiment in the same way as that of conventional investors.

Rest of the paper is organized as follows: we review the relevant literature in the next section, section 3 discusses the data and methodology, section 4 presents the empirical findings and section 5 concludes the paper. 


\section{Literature Review}

\subsection{Theoretical framework}

The theoretical framework of this study centers on the divide between the traditional and behavioral finance theories in the area of asset pricing. The traditional theories propose that all available information in the market is reflected in the price of assets, and at any time, trading by rational investors leads to stock prices equaling the present value of future cash flows (Fama, 1970). In such an efficient market, transaction costs do not exist, investors have sensible preferences, they have access to all information and no asset can earn a return more than what is warranted based on its risk.

However, over the years, certain events such as Black Monday have seen dramatic shocks in stock prices, a phenomenon that the traditional finance theory failed to explain. This led the experts to believe that investors may underreact or overreact to certain market information and this irrational behavior can move a security's price further away from its fundamental value (Kahneman \& Tversky, 1979). The behavioral aspect, now considered an important part of financial decision-making, believes that investors rely on their sentiments when trading, where sentiment means an unfounded belief about future cash flows and risks of a stock.

There are two factors behind the occurrence and persistence of mispricing. First is the speculative demand that results from the irrational trading action. Investors may overreact while trading on some positive news and take amplified positions pushing up the prices more than the level justified by the good news (DeLong, Shleifer, Summers, \& Waldmann, 1990). On the contrary, investors may underreact by not adjusting their positions sufficiently in the light of new public information (Barberis, Shleifer, \& Vishny, 1998). Second factor is the constraint on arbitrage, which implies that it is costly and risky for rational investors to undertake arbitrage against the actions of the sentimental investors, hence prices do not revert to fundamentals so easily.

In the behavioral finance literature, we find two measures of investor sentiment. Investor, consumer or business sentiment surveys provide a direct source of market sentiment (Fisher \& Statman, 2000; Qiu \& Welch, 2004; Lemmon \& Portniaguina, 2006); however, these surveys can misguide because of the discrepancy between what respondents report and how they actually behave. Moreover, data from these are not available in most markets. As an alternative, researchers use different economic and financial variables as indirect proxies to capture sentiment. Though the two measures have their respective advantages and disadvantages, the association between the sentiment and stock prices, is what is of importance. 
Figure 1 illustrates the theoretical framework used to analyze the causal relationship between sentiment and stock returns. Based on this framework, investor's belief (optimism or pessimism) is captured by the sentiment measures that affects the investors trading action and hence affects the aggregate market return. Market return itself could be a triggering event affecting investor's belief and sentiment.

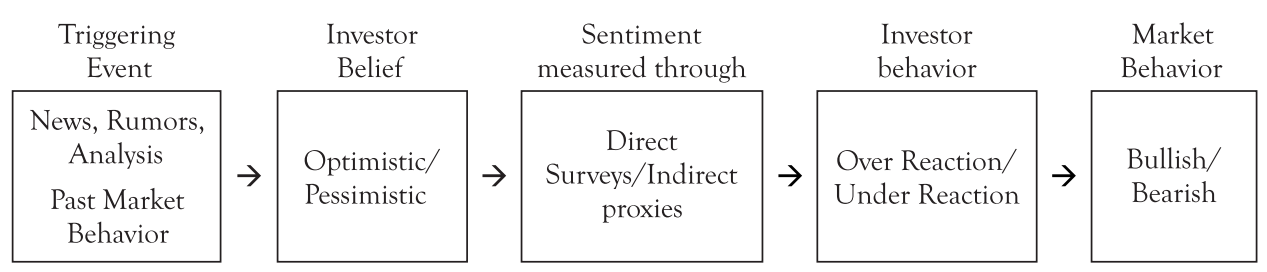

Figure 1: Conceptual Framework of Sentiments and Returns

\subsection{Sentiment proxies}

Because of their easy availability with high frequency data, literature mainly relies on indirect proxies for sentiment measurement. Early researches on sentiment involved using a single proxy to capture sentiment. Lee, Shleifer, and Thaler (1991), for example, used closed-end fund discount, calculated as the difference between the fund's price and net asset value divided by the net asset value, as a measure of investor sentiment. Funds flow to different types of mutual funds, net purchases of funds and proportion of funds assets held in cash are other mutual funds based sentiment proxies used in literature (Brown, 1999; Brown \& Cliff, 2004; Baker \& Wurgler, 2006). Brown and Cliff (2004) introduced advances to declines ratio, calculated as the number of advancing stocks divided by the number of declining stocks, and Baker and Wurgler (2006) used dividend premium calculated as log difference of the average market-tobook ratios of dividend paying and non-paying stocks, as market performance based proxies of investor sentiment. Similarly, there are various sentiment proxies based on trading data and type of trading activity, such as the ratio of short sales to total sales, ratio of odd lot sales to odd lot purchases, number of initial public offerings, stock turnover, relative strength index and money flow index (Baker \& Wurgler, 2006, Chen, Chong, \& Duan, 2010; Alrabadi, 2015). Sentiment proxies based on financial options trading and volatility and on corporate investments have also been used in literature (Lamont, 2000; Dennis \& Stewart, 2002).

Motivated by the behavioral theories and sentiment based explanation of price shocks, there have been developments in the construction of sentiment index. Brown and Cliff (2004) and Baker and Wurgler (2006; 2007) used multiple proxies and extracted the common component from those proxies based on principal component analysis. Since then, their approach has been widely used in capturing investor 
sentiment in different markets with different combinations of proxies.

\subsection{Sentiment and stock return relationship}

Numerous studies have investigated the association between investor sentiment and stock returns with most studies focusing on developed markets. Most studies reported a significant relationship between sentiment and returns; however, there is no consensus on the direction of causality between the two. Many studies (Fisher \& Statman, 2000; Baker \& Wurgler, 2007; Bathia \& Bredin, 2012) reported that sentiment has the predictive power for short-term future returns, while others like Brown and Cliff (2004) reported that stock returns are strong positive predictors of investor sentiment. Furthermore, within the literature supporting that sentiment influences returns, there is disagreement on the direction of influence (Anusakumar, Ali, \& Wooi, 2017).

Limited studies reported findings from emerging markets. Canbas and Kandir (2009), for example, studied the relationship between investor sentiment and equity returns in Istanbul stock market, Chen, Chong, and Duan (2010) calculated the investor sentiment index for Hong Kong stock and Alrabadi (2015) investigates the bi-directional causality between market returns and sentiment in Amman Stock Exchange. Furthermore, Anusakumar et al. (2017) reported that the effect of sentiment on stock returns was not consistent for eight Asian countries: China, India, Indonesia, Malaysia, Philippines, Taiwan, Thailand, and South Korea.

In recent years, as Islamic stocks have emerged as an alternate investment opportunity for investors, researchers have studied role of sentiment and macroeconomic factors on Islamic stock returns. Islamic stocks are screened by strict ethical standards set by Shariah and therefore, these stocks behave differently in bullish and bearish market conditions (Razak, Ismail, \& Aridi, 2016). Merdad, Hassan, and Hippler (2015), for example, documented existence of a significant Islamic effect while investigating the cross-section of returns for stocks from Saudi Arabia, whereas Rashid, Hassan, and Yein (2014) reported that Islamic stocks in Malaysia are affected by macroeconomic variables as well as sentiment in the same way as conventional stocks. Similarly, Narrayan, Phan, Sharma, and Westerlund (2016) used the data of Islamic stocks from multiple countries and also found that Islamic stock returns can be predicted based on financial and macroeconomic variables. Jaziri and Abdelhedi (2018) documented that the Islamic occasions of Ramadan, Eid-ul-Fitr and Hajj Pilgrimage generate positive sentiments in Arab financial markets and these sentiments affect the stock returns positively.

Literature on the effect of sentiment on Islamic stock returns is very limited with 
inconclusive results. The available studies have mainly focused on macroeconomic variables as determinants of Islamic stock returns. However, none of the studies has used principal component analysis approach to construct sentiment and investigate its impact on Islamic stock returns. We hope to fill these gaps in literature by examining the bi-directional causality between investor sentiment and stock returns, taking conventional and Islamic stocks as separate groups, in the post-financial crisis period for Pakistan.

\section{Data and Methodology}

The analysis is performed using data over the period from August 2009 till June 2019. We perform the analysis separately for conventional and Islamic stocks, using percentage change in KSE-100 index as the proxy for conventional stock return (MR) and percentage change in KMI-30 index as proxy for Islamic stock return (IMR). KSE-100 and KMI-30 indices are the most widely used market indices in Pakistan. KSE-100 index is the benchmark for evaluating performance of conventional stocks in Pakistan. Introduced in 1991, it comprises of 100 companies that are selected based on sector representation and free-float capitalization. KMI-30 index is the benchmark for evaluating performance of Islamic stocks in Pakistan. Introduced in 2009, it comprises of 30 companies that are selected based on Shari'ah screening filters and free-float capitalization. Since KMI-30 index was introduced in 2009, we could not include the period prior to that.

For construction of sentiment variables that required firm-level data, our sample included all listed firms for which the needed data was obtainable. In 2009, 652 firms were listed on Pakistan Stock Exchange and in 2019, 546 firms were listed. For constructing clean sentiment index, macroeconomic data on consumer price index, large scale manufacturing index and interest rates are used. We collected the required data from multiple sources. Firm-level data on stock prices, dividends, earnings, trading volume and outstanding shares was taken from Thomson Reuters Data Stream. Data on consumer price index, large scale manufacturing index and interest rates was taken from State Bank of Pakistan and data on KSE-100 and KMI-30 indices was taken from Pakistan Stock Exchange.

Literature documents the use of numerous proxy variables to construct the sentiment index. These variables are broadly categorized into four groups: price-based proxies, volume-based proxies, fund flow-based proxies and derivatives-based proxies. As documented by Kumari and Mahakud (2015), there is no evidence about the precise number of proxies to be used in constructing the sentiment index. We started by listing all the proxies as used in literature. We then eliminated the variables for which sufficient data over the sample period was not available. Our selected process 
resulted in the following six proxy variables which fall under the price-based and volume-based categories:

1. Advances-to-decline (AD) is the ratio of number of shares with positive returns over the number of shares with negative returns. Value of advances-to-decline greater than one indicates bullish market sentiment (Brown \& Cliff, 2004).

2. Premium on dividends (PD) is the log of mean market-to-book ratio of dividend paying stocks minus the log of mean market-to-book ratio of non-dividend paying stocks. A lower premium on dividends suggests that the relative demand for dividend paying stocks which are mainly larger, mature stocks is not very strong and indicates bullish market sentiment (Baker \& Wurgler, 2004).

3. Price-to-earnings $(\mathrm{PE})$ is the mean ratio of market price to earnings per share weighted by the earnings of the company. A high value of price-to-earnings implies that growth expectations are high and indicates bullish market sentiment (Zouaoui, Nouyrigat, \& Beer, 2011).

4. Money Flow $(\mathrm{MF})$ is a technical indicator which captures the flow of money coming in and going out of stocks using stock prices and trading volumes. High value of money flow suggests a higher investor demand in stock market and indicates bullish sentiment (Chen et al., 2010).

5. Relative Strength (RS) is a technical indicator which captures the magnitude of recent stock price changes. High value of relative strength suggests higher investor demand in the stock market and indicates bullish sentiment (Chong \& Ng, 2008).

6. Turnover (TR) is the ratio of trading volume of shares over the number of shares outstanding. Turnover is a measure of market liquidity and a high value of turnover indicates bullish sentiment (Chen et al., 2010).

We constructed monthly sentiment index based on these six proxies. Some of these variables (for example, money flow and relative strength) are same as used in previous studies from Pakistan. However, some of our proxies are different. For example, we do not use the number of initial public offerings as used by Khan and Ahmad (2018) because of the low IPO activity in most months over our sample period. Our selection of different proxies is justified by the availability of satisfactory and reliable data with required frequency over the sample period.

Prior works (Brown \& Cliff, 2004; Baker \& Wurgler, 2006) suggest that each sentiment proxy has a common, sentiment component and an idiosyncratic non-sentiment related component. Hence, a sentiment index can be constructed by taking the common, sentiment component of all proxies using the principal component 
analysis. Following literature, we construct sentiment index () by extracting the common variation of the selected six proxy variables. Baker and Wurgler (2006) argue "principal components analysis cannot distinguish between a common sentiment component and a common business cycle component". Since each of our proxy variable might also be impacted by business cycle, we remove the impact of business cycle from each variable by regressing it on three macroeconomic variables: inflation (proxied by change in consumer price index), industrial production (proxied by change in large scale manufacturing index) and interest rate (proxied by change in six-month Karachi interbank offer rate) and taking the residual series as clean variable series. We construct a clean sentiment index () by applying the principal component analysis on clean variables.

Since sentiment and stock returns may act as a system (Brown \& Cliff, 2004; Mathur \& Rastogi, 2018), we, therefore, use vector autoregressive framework to examine the causality between market sentiment and aggregate stocks returns. We summarize the characteristics of the study sample used for Index construction and in VAR model in Table 1.

Table 1: Characteristics of Study Sample

\begin{tabular}{|c|c|}
\hline $\begin{array}{c}\text { Raw Sentiment } \\
\text { Index }\end{array}$ & $\begin{array}{r}\text { Data and Sampling Criteria } \\
\text { till June 2019. Stocks with available data on prices, shares outstanding, trading } \\
\text { volume, book value, earnings and dividends are used. }\end{array}$ \\
\hline $\begin{array}{c}\text { Clean Senti- } \\
\text { ment Index }\end{array}$ & $\begin{array}{r}\text { Macroeconomic data on consumer price index, large scale manufacturing index } \\
\text { and 6-month Karachi Interbank Offer Rate over the period from August } 2009 \text { till } \\
\text { June 2019 }\end{array}$ \\
\hline $\begin{array}{c}\text { VAR Model } \\
\text { Variables }\end{array}$ & $\begin{array}{r}\text { Market-level data on KSE-100 returns and KMI-30 return and constructed senti- } \\
\text { ment indices over the period from August 2009 till June 2019. }\end{array}$ \\
\hline
\end{tabular}

\section{Empirical Results}

Table 2 reports the descriptive statistics of the sentiment variables and stock returns. Mean values for most variables used in sentiment index construction are close to their respective median values, suggesting that the outliers do not substantially impact the mean values. Mean monthly return on KSE-100 index (MR) was 1.31 percent with monthly standard deviation of 5.09 percent and mean monthly return on KMI-30 index (IMR) was 1.43 percent with monthly standard deviation of 5.21 percent. Over the study period, Islamic stocks have earned a higher mean return and were more volatile compared to conventional stocks in market. 
Figure 2 plots the returns on KSE-100 and KMI-30 indices over the study period. The graph shows that the returns on the two indices do not coincide perfectly. Except for the last one year in the study period, the return on Islamic stocks seems to be leading the returns on conventional stocks. The coefficient of correlation between the two is very low (0.09) suggesting weak co-movements between the two indices.

Our sentiment index (Sentiment) is the first principal component of the six variables explained in section II and is obtained as follows (Equation 1).

$$
\text { Sentiment }_{t}=0.478 A D_{t}-0.219 P D_{t}+0.255 P E_{t}+0.559 M F_{t}+0.541 R S_{t}+0.231 T R_{t}(1)
$$

The sentiment index after removing the impact of business cycle (Clean_Sentiment) is the first principal component of the six clean variables and is obtained as follows (Equation 2).

$$
\text { Clean_Sentiment } t_{t}=0.482 A D_{t}-0.234 P D_{t}+0.246 P E_{t}+0.560 M F_{t}+0.538 R S_{t}+0.225 T R_{t}
$$

In both cases, all six variables have taken the theoretically correct sign. Advances-to-decline, price-to-earnings, money flow, relative strength and turnover rate which are the bullish indicators have positive signs suggesting that an increase in any of these variables increases the market sentiment. Premium on dividend which is a bearish indicator has a negative sign suggesting that sentiment increases when dividend premium falls.

Table 3 presents the pairwise correlation coefficients for the six sentiment variables and the sentiment index. Correlation figures for raw variables and sentiment index are presented in panel $\mathrm{A}$ and correlation figures for clean variables and clean sentiment index are presented in panel B. All variables have a strong correlation with the constructed index with the predicted sign. Correlation between variables is also strong and significant in most cases. The correlation matrix does not change substantially and the correlations remain strong after removing the business cycle impact.

We estimate the vector autoregressive (VAR) models using both raw and clean sentiment. We checked the stationarity of the variable series used in the model using Dicky-Fuller Test. We also confirmed the absence of cointegration between the variable series using Johansen Cointegration Test. In VAR model, we include the return and sentiment as covariates and do not include other exogenous variables, specifically macroeconomic variables. The omitted variables may lead to unobserved heterogeneity and endogeniety issues. However, we choose not to include macroeconomic variables in the model as we have already excluded their impact while generating the clean sentiment series. Moreover, the VAR model controls for endogeneity by including the lagged values of dependent variable as explanatory variables (Ullah, Akhtar, \& Zaefarian, 2018). 
Table 2: Descriptive Statistics, August 2009 to June 2019

\begin{tabular}{|c|c|c|c|c|c|}
\hline & Mean & Median & Minimum & Maximum & $\begin{array}{c}\text { Standard } \\
\text { Deviation }\end{array}$ \\
\hline \multicolumn{5}{|l|}{ Proxies for sentiment } \\
\hline AD & 1.24 & 0.91 & 0.10 & 5.56 & 1.05 \\
\hline PD & 0.38 & 0.47 & -1.39 & 1.98 & 0.62 \\
\hline PE & 11.64 & 11.56 & 5.05 & 19.35 & 3.91 \\
\hline MF & 54.09 & 54.49 & 38.04 & 68.65 & 7.12 \\
\hline RS & 48.75 & 48.81 & 39.76 & 61.96 & 4.57 \\
\hline TR & 0.17 & 0.05 & 0.01 & 3.06 & 0.44 \\
\hline Proxies for stocks return & 1.31 & 1.97 & -11.17 & 13.95 & 5.09 \\
\hline MR & 1.43 & 1.93 & -11.94 & 14.51 & 5.21 \\
\hline IMR & & & & \\
\hline
\end{tabular}

The table reports the monthly summary statistics for the six variables used to construct market sentiment index and for conventional and Islamic stocks' returns. Advances-to-decline (AD), premium on dividends (PD), price-to-earnings (PD) and relative strength (RS) are market performance related sentiment measures and money flow (MF) and turnover rate (TR) are trading volume related sentiment measures. MR is the percentage return on KSE-100 index which is used as a proxy for conventional stocks return and IMR is the percentage return on KMI-30 index which is used as a proxy for Islamic stocks return. Data consists of 119 monthly observations over the period from August 2009 to June 2019.

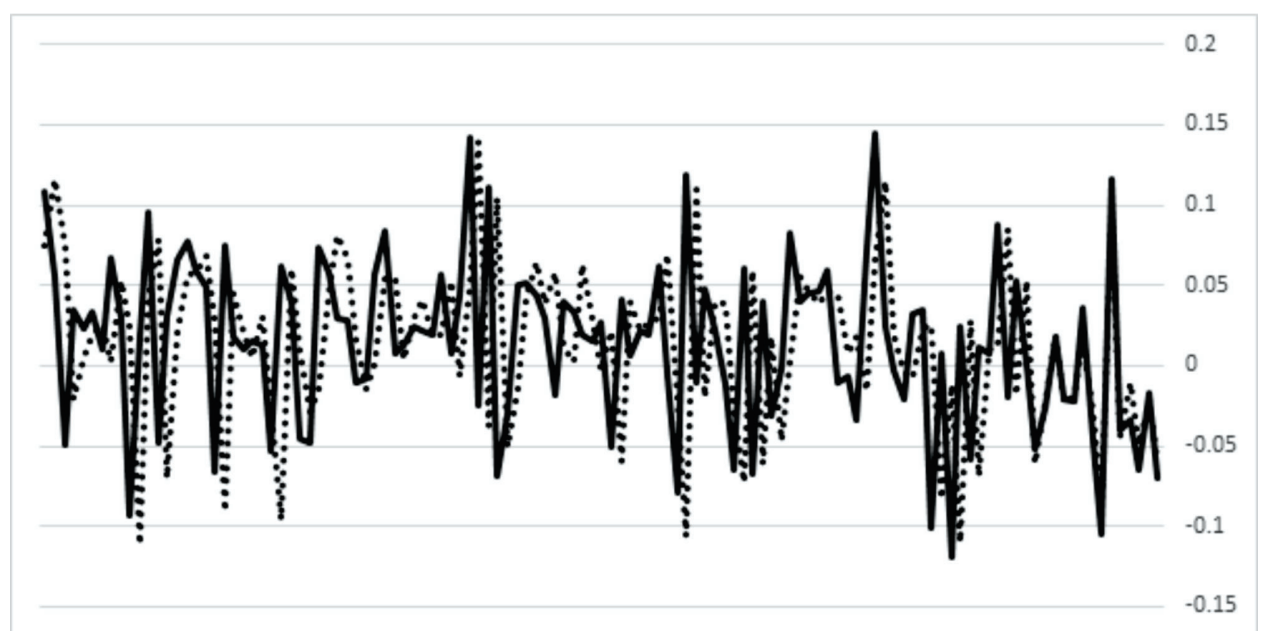

Figure 2: Returns on conventional and Islamic stocks, August 2009 to June 2019

The dotted line is the monthly percentage return on KSE-100 index which is the proxy for conventional stocks return (MR) and the solid line is the monthly percentage return on KMI-30 index which is the proxy for Islamic stocks return (IMR). Conventional and Islamic stock returns tend to move together; however, the two do not coincide perfectly for majority of the months over the study period. 
Table 3: Correlations between Sentiment Variables

\begin{tabular}{|c|c|c|c|c|c|c|c|}
\hline \multicolumn{7}{|c|}{ PANEL A: Raw Variables } \\
\hline & AD & PD & PE & MF & RS & TR & Sentiment \\
\hline AD & 1.00 & & & & & & \\
\hline PD & -0.12 & 1.00 & & & & & \\
\hline PE & 0.12 & $-0.26^{* * *}$ & 1.00 & & & & \\
\hline MF & $0.68^{* * *}$ & $-0.23^{* * *}$ & $0.26^{* * *}$ & 1.00 & & & \\
\hline RS & $0.68^{* * *}$ & $-0.20^{* *}$ & $0.17^{*}$ & $0.90^{* * *}$ & 1.00 & & \\
\hline TR & 0.16 & -0.09 & $0.41^{* * *}$ & $0.22^{* *}$ & $0.15^{* *}$ & 1.00 & \\
\hline Sentiment & $0.79^{* * *}$ & $-0.36^{* * *}$ & $0.42^{* * *}$ & $0.93^{* * *}$ & $0.90^{* * *}$ & $0.38^{* * *}$ & 1.00 \\
\hline \multicolumn{7}{|c|}{} & \multicolumn{2}{|c|}{ PANEL B: Clean Variables } & & \\
\hline \multicolumn{2}{|c|}{ AD } & PD & PE & MF & RS & TR & Clean Senti- \\
ment
\end{tabular}

The table reports pairwise correlation between six variables used to construct sentiment index and the resulting index. Panel A reports correlations between raw variables and sentiment and panel B reports correlations between clean variables and clean sentiment. Correlations are calculated using 119 monthly observations from August 2009 to June 2019. ${ }^{*}$ indicates significance at 10 percent, ${ }^{* *}$ indicates significance at 5 percent and ${ }^{* *}$ indicates significance at 1 percent.

Estimation results using raw sentiment and stock returns as covariates are presented in Table 4 and estimation results using clean sentiment and stock returns as covariates are presented in Table 5. Based on various lag selection criteria, we use the lag of two months in both models. Panel $\mathrm{A}$ in the two tables show the results when the variables are sentiment and conventional stock returns and Panel B in the two tables show the results when the variables are sentiment and Islamic stock returns. The results in Panel A of both models show that our sentiment index is a strong predictor of conventional stock returns. Lagged sentiment and conventional stock returns explain 39 percent of total variation in conventional stock returns. High value of F-statistics in the models suggest strong joint significance of independent variables. Both one- and two-month lags are significant with different signs. The one-month lagged sentiment 
affects the contemporaneous conventional stock return with a positive sign and the two-month lagged sentiment affects the contemporaneous conventional stock return with a negative sign. The results show that the sentiment based trading actions of the investors cause persistence in returns for one month and provide evidence of 'hold more effect'. As the investors become more bullish and they buy more stocks, their trading increases the level of market risk and the expected returns increase. However, in two months' time, the return pattern reverses showing evidence of 'price pressure effect'. As the stocks become overpriced and the higher prices translate into lower returns. In line with Sadaqat and Butt (2016), our results confirm the presence of 'hold more' effect and 'price pressure effect' for conventional stock in Pakistan; however, our findings suggest a longer hold out effect (for 1 month) and a delayed price pressure (in 2 months) compared to the previous study.

The results in Panel B of both models (Tables 4 and 5) show that Islamic stock returns are not affected by market sentiment. None of the coefficient of lagged sentiment or F-statistic is significant. In all cases, lagged sentiment is found to have a significantly positive effect on contemporaneous sentiment; however, lagged conventional stock returns do not seem to have an impact on current sentiment.

There is mixed evidence on the specification which reveals the impact of sentiment on return; therefore, we also estimate the VAR models using the sentiment change in place of sentiment level. Table 6 reports the estimation results using raw sentiment change and Table 7 reports the estimation results using clean sentiment change. Based on various lag selection criteria, we use the lag of three months in both models. Panel A in the two tables show the results when the variables are conventional stock returns and sentiment change and Panel B in the two tables show the results when the variables are Islamic stock returns and sentiment change. The results in Panel A of both models show that change in sentiment index influences conventional stock returns with all three lags being positive and significant. The positive effect is

Table 4: Monthly VAR, Stock Returns and Sentiment

\begin{tabular}{|c|c|c|c|c|}
\hline \multirow{2}{*}{ Dependent variable } & \multicolumn{2}{|c|}{ Panel A: Conventional Stocks } & \multicolumn{2}{c|}{ Panel B: Islamic Stocks } \\
\cline { 2 - 5 } & $\mathrm{MR}_{\mathrm{t}}$ & Clean_Sentiment $\mathrm{t}_{\mathrm{f}}$ & $\mathrm{IMR}_{\mathrm{t}}$ & Clean_Sentiment $_{\mathrm{t}}$ \\
\hline Constant & $0.02^{* * *}$ & 0.03 & $0.01^{* *}$ & -0.02 \\
\hline & $(3.73)$ & $(0.17)$ & $(2.49)$ & $(-0.12)$ \\
\hline Clean_Sentiment $_{\mathrm{t}-1}$ & $0.02^{* * *}$ & $0.38^{* * *}$ & 0.00 & $0.33^{* *}$ \\
\hline & $(8.72)$ & $(4.04)$ & $(-0.93)$ & $(2.56)$ \\
\hline Sentiment $_{\mathrm{t}-2}$ & $-0.01^{*}$ & 0.13 & 0.00 & 0.16 \\
\hline & $(-1.75)$ & $(1.16)$ & $(0.85)$ & $(1.37)$ \\
\hline
\end{tabular}




\begin{tabular}{|c|c|c|c|c|}
\hline $\mathrm{MR}_{\mathrm{t}-1} / \mathrm{IMR}_{\mathrm{t}-1}$ & $-0.20^{* *}$ & -0.29 & -0.02 & 2.15 \\
\hline $\mathrm{MR}_{\mathrm{t}-1} / \mathrm{IMR}_{\mathrm{t}-2}$ & $(-2.23)$ & $(-0.08)$ & $(-0.17)$ & $(0.56)$ \\
\hline & -0.06 & -2.32 & -0.01 & -1.45 \\
\hline Adjusted R-squared & $(-0.74)$ & $(-0.76)$ & $(-0.12)$ & $(-0.44)$ \\
\hline F-statistics & 0.39 & 0.16 & -0.01 & 0.16 \\
\hline
\end{tabular}

The table reports the estimation results of vector autoregressive models. Variables in panel A are conventional stock returns (MR) and the raw sentiment. Variables in panel B are Islamic stock returns (IMR) and the raw sentiment. Raw sentiment (Sentiment) is the first principal component of six variables: advances-to-decline, premium on dividends, price-to-earnings, relative strength, money flow and turnover rate. MR is the percentage return on KSE-100 index and is used as a proxy for conventional stock return. IMR is the percentage return on KMI-30 index and is used as a proxy for Islamic stock return. Two lags are used in estimation model based on multiple lag length criteria. Estimation uses 119 monthly observations over the period from August 2009 to June 2019. * indicates significance at 10 percent, ${ }^{* *}$ indicates significance at 5 percent and ${ }^{* * *}$ indicates significance at 1 percent.

Table 5: Monthly VAR, Stock Returns and Clean Sentiment

\begin{tabular}{|c|c|c|c|c|}
\hline \multirow{2}{*}{ Dependent variable } & \multicolumn{2}{|c|}{ Panel A: Conventional Stocks } & \multicolumn{2}{c|}{ Panel B: Islamic Stocks } \\
\cline { 2 - 5 } & $\mathrm{MR}_{\mathrm{t}}$ & Clean_Sentiment & $\mathrm{IMR}_{\mathrm{t}}$ & Clean_Sentiment $_{\mathrm{t}}$ \\
\hline Constant & $0.02^{* * *}$ & 0.03 & $0.01^{* *}$ & -0.02 \\
\hline & $(3.73)$ & $(0.17)$ & $(2.49)$ & $(-0.12)$ \\
\hline Clean_Sentiment $_{\mathrm{t}-1}$ & $0.02^{* * *}$ & $0.38^{* * *}$ & 0.00 & $0.33^{* *}$ \\
\hline & $(8.72)$ & $(4.04)$ & $(-0.93)$ & $(2.56)$ \\
\hline Clean_Sentiment $_{\mathrm{t}-2}$ & $-0.01^{*}$ & 0.13 & 0.00 & 0.16 \\
\hline & $(-1.75)$ & $(1.16)$ & $(0.85)$ & $(1.37)$ \\
\hline MR $_{\mathrm{t}-1} / \mathrm{IMR}_{\mathrm{t}-1}$ & $-0.20^{* *}$ & -0.29 & -0.02 & 2.15 \\
\hline MR $_{\mathrm{t}-2} / \mathrm{IMR}_{\mathrm{t}-2}$ & $(-2.23)$ & $(-0.08)$ & $(-0.17)$ & $(0.56)$ \\
\hline & -0.06 & -2.32 & -0.01 & -1.45 \\
\hline Adjusted R-squared & $(-0.74)$ & $(-0.76)$ & $(-0.12)$ & $(-0.44)$ \\
\hline F-statistics & 0.39 & 0.16 & -0.01 & 0.16 \\
\hline
\end{tabular}

The table reports the estimation results of vector autoregressive models. Variables in panel A are conventional stock returns (MR) and the clean sentiment. Variables in panel B are Islamic stock returns (IMR) and the clean sentiment. Impact of business cycle is removed from six sentiment variables to obtain clean variables and clean sentiment index (Clean_Sentiment) is the first principal component of six clean variables. MR is the percentage return on KSE-100 index and is used as a proxy for conventional stock return. IMR is the percentage return on KMI-30 index and is used as a proxy for Islamic stock return. Two lags are used in estimation model based on multiple lag length criteria. Estimation uses 119 monthly observations over the period from August 2009 to June 2019. * indicates significance at 10 percent, ${ }^{* *}$ indicates significance at 5 percent and ${ }^{* * *}$ indicates significance at 1 percent. 
consistent with theoretical belief that as sentiment increases (decreases), the return is expected to rise (fall). Overall model is significant with high F-statistic and adjusted $R$-squared values. For Islamic stock in panel B in two tables (6 and 7), none of the coefficient of sentiment change is significant.

With results presented above, the study confirms the significant role of market sentiment in setting the direction of subsequent conventional stock returns in Pakistan and provides evidence that Islamic stock returns are not influenced by market sentiment. Our findings about the Islamic stock return being independent of sentiment are unique and an important contribution to the literature on determinants of Islamic stock returns. These findings are in contrast to the ones reported by Rashid et al. (2014) for Islamic stocks in Malaysia. Their study reported sentiment to have a strong impact on Islamic along with conventional stocks in Malaysia. The contradictory findings for Islamic stocks of Pakistan and Malaysia could be related to the difference in development stage of Islamic finance in the two countries. In Malaysia, establishment of Islamic capital markets started in 1990s and the country is now considered as one of the top Islamic markets where more than 70 percent of constituents of conventional index are Islamic stocks (Mustafa, Ramlee, \& Kassim, 2017). In such case, all investors, regardless of their religious beliefs, will be trading in Islamic stocks resulting in commonality in return behavior of conventional and Islamic stocks. Contrary to this, Islamic capital markets in Pakistan are comparatively young and Islamic stocks comprise of less than 50 percent of listed stocks. Due to the bigger available pool of conventional stocks, Islamic stocks in Pakistan are more likely to attract the investors with religious bindings.

Table 6: Monthly VAR, Stock Returns and Sentiment Changes

\begin{tabular}{|c|c|c|c|c|}
\hline \multirow{2}{*}{ Dependent variable } & \multicolumn{2}{|c|}{ Panel A: Conventional Stocks } & \multicolumn{2}{c|}{ Panel B: Islamic Stocks } \\
\cline { 2 - 5 } & $\mathrm{MR}_{\mathrm{t}}$ & $\Delta$ Sentiment & $\mathrm{IMR}_{\mathrm{t}}$ & $\Delta$ Sentiment $_{\mathrm{t}}$ \\
\hline Constant & $0.01^{* *}$ & 0.16 & $0.01^{* *}$ & 0.16 \\
\hline & $(2.26)$ & $(0.99)$ & $(2.33)$ & $(0.95)$ \\
\hline$\Delta$ Sentiment $_{\mathrm{t}-1}$ & $0.02^{* * *}$ & $-0.51^{* * *}$ & 0.00 & $-0.44^{* * *}$ \\
\hline & $(8.56)$ & $(-5.34)$ & $(-0.64)$ & $(-3.72)$ \\
\hline$\Delta$ Sentiment $_{\mathrm{t}-2}$ & $0.01^{* * *}$ & $-0.32^{* * *}$ & 0.00 & $-0.25^{* *}$ \\
\hline & $(4.62)$ & $(-2.63)$ & $(-0.29)$ & $(-2.08)$ \\
\hline$\Delta$ Sentiment $_{\mathrm{t}-3}$ & $0.01^{* *}$ & -0.08 & 0.00 & -0.05 \\
\hline & $(2.60)$ & $(-0.75)$ & $(0.28)$ & $(-0.45)$ \\
\hline $\mathrm{MR}_{\mathrm{t}-1} / \mathrm{IMR}_{\mathrm{t}-1}$ & $-0.17^{*}$ & -2.09 & -0.05 & -2.04 \\
\hline & $(-1.92)$ & $(-0.59)$ & $(-0.38)$ & $(-0.56)$ \\
\hline
\end{tabular}




\begin{tabular}{|c|c|c|c|c|}
\hline $\mathrm{MR}_{t-2} / \mathrm{IMR}_{\mathrm{t}-2}$ & 0.08 & $-8.32^{* *}$ & 0.04 & -3.22 \\
\hline $\mathrm{MR}_{t-3} / \mathrm{IMR}_{\mathrm{t}-3}$ & $(0.96)$ & $(-2.43)$ & $(0.29)$ & $(-0.89)$ \\
\hline & $0.29^{* * *}$ & -3.42 & 0.00 & $-6.75^{*}$ \\
\hline Adjusted R-squared & $(3.64)$ & $(-1.10)$ & $(-0.00)$ & $(-1.85)$ \\
\hline F-statistics & 0.39 & 0.20 & -0.04 & 0.18 \\
\hline
\end{tabular}

The table reports the estimation results of vector autoregressive models. Variables in panel A are conventional stock returns (MR) and change in raw sentiment ( $\Delta$ Sentiment). Variables in panel B are Islamic stock returns (IMR) and change in raw sentiment ( $\Delta$ Sentiment). $\Delta$ Sentiment is calculated as the difference between current month's and previous month's sentiment. MR is the percentage return on KSE-100 index and is used as a proxy for conventional stock return. Sentiment is the first principal component of the six sentiment variables. IMR is the percentage return on KMI-30 index and is used as a proxy for Islamic stock return. Three lags are used in estimation model based on multiple lag length criteria. Estimation uses 118 monthly observations over the period from September 2009 to June 2019. ${ }^{*}$ indicates significance at 10 percent, ${ }^{* *}$ indicates significance at 5 percent and ${ }^{* * *}$ indicates significance at 1 percent.

Table 7: Monthly VAR, Stock Returns and Clean Sentiment Changes

\begin{tabular}{|c|c|c|c|c|}
\hline \multirow{2}{*}{ Dependent variable } & \multicolumn{2}{|c|}{ Panel A: Conventional Stocks } & \multicolumn{2}{c|}{ Panel B: Islamic Stocks } \\
\cline { 2 - 5 } & $\mathrm{MR}_{\mathrm{t}}$ & $\Delta$ Sentiment & $\mathrm{IMR}_{\mathrm{t}}$ & $\Delta$ Sentiment $_{\mathrm{t}}$ \\
\hline \multirow{2}{*}{ Constant } & $0.01^{* *}$ & 0.18 & $0.01^{* *}$ & 0.19 \\
\hline$\Delta$ Sentiment $_{\mathrm{t}-1}$ & $(2.23)$ & $(1.07)$ & $(2.35)$ & $(1.08)$ \\
\hline & $0.02^{* * *}$ & $-0.05^{* * *}$ & 0.00 & $-0.50^{* * *}$ \\
\hline$\Delta$ Sentiment $_{\mathrm{t}-2}$ & $(8.48)$ & $(-5.69)$ & $(-0.96)$ & $(-4.08)$ \\
\hline & $0.01^{* * *}$ & $-0.31^{* *}$ & 0.00 & $-0.26^{* *}$ \\
\hline$\Delta$ Sentiment $_{\mathrm{t}-3}$ & $(4.54)$ & $(-2.55)$ & $(-0.57)$ & $(-2.08)$ \\
\hline & $0.01^{* *}$ & -0.03 & 0.00 & 0.01 \\
\hline $\mathrm{MR}_{\mathrm{t}-1} / \mathrm{IMR}_{\mathrm{t}-1}$ & $(2.52)$ & $(-0.27)$ & $(0.61)$ & $(0.04)$ \\
\hline & $-0.17^{*}$ & -3.23 & -0.02 & -1.43 \\
\hline $\mathrm{MR}_{\mathrm{t}-2} / \mathrm{IMR}_{\mathrm{t}-2}$ & $(-1.91)$ & $(-0.88)$ & $(-0.12)$ & $(-0.37)$ \\
\hline & 0.10 & $-9.12^{* *}$ & 0.05 & -4.32 \\
\hline $\mathrm{MR}_{\mathrm{t}-3} / \mathrm{IMR}_{\mathrm{t}-3}$ & $(1.11)$ & $(-2.56)$ & $(0.40)$ & $(-1.13)$ \\
\hline
\end{tabular}




\begin{tabular}{|c|c|c|c|c|}
\hline & $(3.43)$ & $(-0.86)$ & $(-0.37)$ & $(-2.04)$ \\
\hline Adjusted R-squared & 0.38 & 0.22 & -0.03 & 0.21 \\
\hline F-statistics & $12.55^{* * *}$ & $6.44^{* * *}$ & 0.49 & $6.00^{* * *}$ \\
\hline
\end{tabular}

The table reports the estimation results of vector autoregressive models. Variables in panel A are conventional stock returns (MR) and change in clean sentiment ( $\Delta$ Clean_Sentiment). Variables in panel B are Islamic stock returns (IMR) and change in clean sentiment ( $\Delta$ Clean_Sentiment). Impact of business cycle is removed from six sentiment variables to obtain clean variables and clean sentiment is the first principal component of the clean variables. $\Delta$ Clean_Sentiment is calculated as the difference between current month's and previous month's clean sentiment. MR is the percentage return on KSE-100 index and is used as a proxy for conventional stock return. IMR is the percentage return on KMI-30 index and is used as a proxy for Islamic stock return. Three lags are used in estimation model based on multiple lag length criteria. Estimation uses 118 monthly observations over the period from September 2009 to June 2019.

\section{Conclusion}

The study examines the bidirectional causality between market sentiment and returns for conventional and Islamic stocks in Pakistan over the period from August 2009 to June 2019. We construct monthly market sentiment index by taking the first principal component of six variables: advances-to-decline, premium on dividends, price-to-earnings, relative strength, money flow and turnover rate. Our results of vector autoregressive models show unidirectional causality running from market sentiment to stock returns. However, the level and change in sentiment has a strong predictive power for subsequent conventional stock returns only. In contrast, sentiment levels and changes are not useful in predicting Islamic stock returns.

The test in our study provide support for the hold more and price pressure effects for conventional stocks in Pakistan; however, our results suggest a longer hold more effect and a delayed price pressure effect. Furthermore, our findings about no association between sentiment and Islamic returns is a unique and important contribution to the literature on Islamic financial markets.

This is the first study that investigates the causal linkages between market sentiment and Islamic stocks in Pakistan. Our contrasting results regarding the relationship between sentiment and returns for conventional and Islamic stocks are justified by the fact that the two indices have different composition criteria and hence the returns on Islamic stock index are not strongly correlated to the returns on conventional stock index in Pakistan. Our results also indicate that the trading behavior of the investors in Islamic stocks differs from investors in conventional stocks. While the conventional stocks' investors get influenced by sentiment and they get involved in speculative trading, we do not get evidence for similar behavior for investors in Islamic stocks. Our results support the fact that the Islamic financial assets that are traded alongside 
the conventional assets in Pakistan have been able to maintain their uniqueness and attract the appropriate investors.

The findings we report have important implications for investors. The fact that equity market stands as the prime candidate for risk sharing making investment in screened stocks permissible from a Shari'ah perspective along with the evidence that returns in Islamic stocks have no connection to market sentiment can be compelling factor encouraging the prospective Muslim investors towards Islamic equities. The knowledge that Islamic assets refrain from the speculative price behavior along with previous literature that documents Islamic stocks performance to be at least as good as the conventional stock can be a comfort to the Muslim Investors and may serve as the catalyst to further stimulate the growth of Islamic assets.

Research interest in Islamic equities is growing and there are many areas of this subject which need investigation. Stock returns are affected by various macroeconomic and fundamental factor apart from the behavioral factors, future study can test if the Islamic stock returns can be explained by these factors. The element of speculation is a central focus of debate in Islamic finance. Many scholars argue that Islamic capital markets should not allow speculative trading and our finding also supports non-dominating role of speculative traders in Islamic equity market. However, the presence of speculators provides liquidity to the market. It would be interesting to investigate the difference in liquidity of conventional and Islamic equities resulting due to the difference in trading behavior of investors in the two markets.

\section{References}

Alrabadi, D. W. H. (2015). A new proxy for investor sentiment: Evidence from an emerging market. Afro-Asian Journal of Finance and Accounting, 5(4), 334-343.

Anusakumar, S. V., Ali, R., \& Hooy, C. H. (2017). The effect of investor sentiment on stock returns: Insight from emerging Asian markets. Asian Academy of Management Journal of Accounting Eु Finance, 13(1), 159-178.

Arif, S., \& Lee, C. M. C. (2014). Aggregate investment and investor sentiment. The Review of Financial Studies, 27(11), 3241-3279.

Baker, M., \& Wurgler, J. (2004). A catering theory of dividends. The Journal of Finance, 59(3), 1125-1165.

Baker, M. \& Wurgler, J. (2006). Investor sentiment and the cross\section of stock returns. The Journal of Finance, 61(4), 1645-1680.

Baker, M. \& Wurgler, J. (2007). Investor sentiment in the stock market. Journal of Economic Perspectives, 21(2), 129-152. 
Barberis, N., Shleifer, A., \& Vishny, R. (1998). A model of investor sentiment. Journal of Financial Economics, 49(3), 3070345.

Barberis, N., \& Thaler, R. H. (2003). A survey of behavioral finance. In G. M. Constantinides, M. Harris, \& R. M. Stulz (Eds.), Handbook of the Economics of Finance. (pp.1053-1128). Amsterdam, NH: Elsevier.

Bathia, D., \& Bredin, D. (2012). An examination of investor sentiment effect on G7 stock market returns. The European Journal of Finance, 19(9), 909-937.

Brown, G. W. (1999). Volatility, sentiment, and noise traders. Financial Analysts Journal, 55(2), 82-90.

Brown, G. W., \& Cliff, M. T. (2004). Investor sentiment and the near-term stock market. Journal of Empirical Finance, 11(1), 1-27.

Canba】, S., \& Kandır, S. Y. (2009). Investor sentiment and stock returns: Evidence from Turkey. Emerging Markets Finance and Trade, 45(4), 36-52.

Chen, H., Chong, T. T., \& Duan, X. (2010). A principal-component approach to measuring investor sentiment. Quantitative Finance, 10(4), 339-347.

Chong, T. T. -L., \& Ng, W. -K. (2008). Technical analysis and the London stock exchange: Testing the MACD and RSI rules using the FT30. Applied Economics Letters, 15(14), 1111-1114.

DeLong, J. B., Shleifer, A., Summers, L. H., \& Waldmann, R. J. (1990). Positive feedback investment strategies and destabilizing rational speculation. The Journal of Finance, 45(2), 379-395.

Dennis, P., \& Stewart, M. (2002). Risk-neutral skewness: Evidence from stock options. Journal of Financial E Quantitative Analysis, 37(3), 471-493.

Edbiz Consulting. (2019). Global Islamic finance report. http://www.gifr.net/publications/gifr2019/ifci.pdf

Fama, E. F. (1970). Efficient capital markets: A review of theory and empirical work. The Journal of Finance, 25(2), 383-417.

Fisher, K. L., \& Statman, M. (2000). Investor sentiment and stock returns. Financial Analyst Journal, $56(2), 16-23$.

Gao, Z., Ren, H. \& Zhang, B. (2016). Googling investor sentiment around the world. Journal of Financial and Quantitative Analysis, 55(2), 549-580.

Haider, A., Din, M., \& Ghani, E. (2011). Consequences of political instability, governance and bureaucratic corruption on inflation and growth: The case of Pakistan. The Pakistan Development Review, 50(4), 773-807.

Jaziri, M., \& Abdelhedi, M. (2018). Islamic occasions and investor sentiment. International Journal of Islamic and Middle Eastern Finance and Management, 11(2), 194-212.

Kahneman, D., \& Tversky, A. (1979). Prospect theory: An analysis of decision under risk. Econometrica, 47(2), 263-291. 
Khan, M. A., \& Ahmad, E. (2018). Measurement of investor sentiment and its bi-directional contemporaneous and lead-lag relationship with returns: Evidence from Pakistan. Sustainability, 11(1), 1-20.

Kumari, J., \& Mahakud, J. (2015). Does investor sentiment predict the asset volatility? Evidence from emerging stock market India. Journal of Behavioral and Experimental Finance, 8, 25-39.

Lamont, A. O. (2000). Investment plans and stock returns. The Journal of Finance, 55(6), 2719-2745.

Lee, C., Shleifer, M. A., \& Thaler, R. H. (1991). Investor sentiment and the closedlend fund puzzle. The Journal of Finance, 46(1), 75-109.

Lemmon, M., \& Portniaguina, E. (2006). Consumer confidence and asset prices: Some empirical evidence. Review of Financial Studies, 19(4), 1499-529.

Masih, M., Kamil, N. K. M., \& Bacha, O. I. (2018). Issues in Islamic equities: A literature survey. Emerging Markets Finance and Trade, 54(1), 1-26.

Merdad, H. J., Hassan, M. K. \& Hippler, W. (2015). The Islamic risk factor in expected stock returns: An empirical study in Saudi Arabia. Pacific-Basin Finance Journal, 34, 293-314.

Mustafa, S. T., Ramlee, R., \& Kassim, S. (2017). Economic forces and Islamic stock market: Empirical evidence from Malaysia. Asian Journal of Business and Accounting, 10(1), 45-85.

Narrayan, P. K., Phan, D. H. B., Sharma, S. S., \& Westerlund, J. (2016). Are Islamic stock returns predictable? A global perspective. Pacific-Basin Finance Journal, 40(PA), 210-223.

Pakistan Stock Exchange. (2019). Re-Composition of PSX KMI-All share Islamic index of Pakistan. Retrieved from https://www.psx.com.pk/psx/themes/psx/uploads/PSX-KMI-ALL-SHARE-INDEX-NOTICE-JUNE-2018-min.pdf

Qiu, L. \& Welch, I. (2004). Investor Sentiment Measures (NBER Working Paper 10794). Cambridge, MA: National Bureau of Economic Research. Retrieved from National Bureau of Economic Research: http://www.nber.org/papers/w10794

Rashid, M., Hassan, M. K., \& Yein, N. Y. (2014). Macroeconomics, investor sentiment, and Islamic stock price index in Malaysia. Journal of Economic Cooperation and Development, 35(4), 219-234.

Razak, R. A., Ismail, N., \& Aridi, N. A. (2016). Is Islamic stock market no different than conventional stock market? An evidence from Malaysia. International Business Management, 10(17), 3914-3920.

Sadaqat, M., \& Butt, H. A. (2016). Modeling sentiment, temporal volatility and excess returns: Empirical evidence from segmented stock market. Journal of Business $\mathcal{E}$ Economics, 8(2), 202-228.

State Bank of Pakistan. (2019). Islamic Banking Bulletin. Retrieved from http://www.sbp.org.pk/ibd/ Bulletin/2019/Sep.pdf

Tauseef, S., \& Nishat, M. (2018). Can investors benefit from momentum trading? Evidence from an emerging market. Business Review, 13(1), 21-36. 
Ullah, S., Akhtar, P., \& Zaefarian, G. (2019). Dealing with endogeniety bias: The generalized method of moments (GMM) for panel data. Industrial Marketing Management, 71, 69-78.

Zouaoui, M., Nouyrigat, G., \& Beer, F. (2011). How does investor sentiment affect stock market crises? Evidence from panel data. The Financial Review, 46(4), 723-747. 
